\title{
Bench Assessment of the Effect of a Collapsible Tube on the Efficiency of a Mechanical Insufflation-Exsufflation Device
}

\author{
Romain Lachal, Bruno Louis, Fabien Subtil, and Claude Guérin
}

\begin{abstract}
BACKGROUND: Collapsibility of upper airways may impair the efficacy of mechanical insufflation-exsufflation (MI-E) devices. The aim of this study was to determine the effect of a collapsible tube on peak expiratory flow (PEF) when using an MI-E device. METHODS: An MI-E device was attached to a lung simulator. Resistance was set at 5 and $20 \mathrm{~cm} \mathrm{H} \mathrm{H}_{2} \mathrm{O} / \mathrm{L} / \mathrm{s}(\mathrm{R5}, \mathrm{R20})$ for compliance settings of 20,40, and $60 \mathrm{~mL} / \mathrm{cm} \mathrm{H}_{2} \mathrm{O}(\mathrm{C20}, \mathrm{C40}, \mathrm{C60})$. A series of 5 cycles were delivered at 3 pressures in the following order: $+30 /-30,+40 /-40$, and $+50 /-50 \mathrm{~cm} \mathrm{H}_{2} \mathrm{O}$ for each compliance/resistance combination with and without the collapsible tube. Each respiratory mechanics profile was tested in random order. Pressure and flow were measured upstream of the MI-E device, and the primary outcome measure was PEF. The relationships of PEF to maximum expiratory pressure were compared with and without the collapsible tube using a linear regression model. RESULTS: For the C20-R5 condition, the effect of the collapsible tube on the intercept $\left(-0.35 \mathrm{~cm} \mathrm{H}_{2} \mathrm{O}\right)$ was not significant, but this was offset by a significant (and the largest) increase in slope $\left(+0.12 \mathrm{~L} / \mathrm{s} / \mathrm{cm} \mathrm{H}_{2} \mathrm{O}\right)$. For the C60-R20 condition, the effect of the collapsible tube on the slope $\left(-0.003 \mathrm{~L} / \mathrm{s} / \mathrm{cm} \mathrm{H}_{2} \mathrm{O}\right)$ was not significant, but this was offset by a significant (and the largest) increase of the intercept $\left(+3.16 \mathrm{~cm} \mathrm{H}_{2} \mathrm{O}\right)$ at $30 \mathrm{~cm} \mathrm{H}_{2} \mathrm{O}$ expiratory pressure. For the other conditions, the collapsible tube significantly increased $\mathrm{PEF}$ at $30 \mathrm{~cm} \mathrm{H}_{2} \mathrm{O}$ expiratory pressure, and the gap further increased above this pressure as the slope increased with the collapsible tube. CONCLUSIONS: The collapsible tube resulted in a higher PEF for all respiratory mechanics profiles tested. Key words: mechanical insufflation-exsufflation; cough; neuromuscular disease; upper airway collapsibility. [Respir Care 2019;64(7):752-759. (C 2019 Daedalus Enterprises]
\end{abstract}

\section{Introduction}

The purpose of a cough is to protect the airways from inhaled external particles and to clear bronchial secretions. The mechanism involves 3 stages. ${ }^{1,2}$ First, the lung volume increases above the functional residual capacity by contraction of the inspiratory muscles. Second, both pleural and alveolar pressures increase up to $300 \mathrm{~cm} \mathrm{H}_{2} \mathrm{O}$ due to closure of the glottis, and the expiratory muscles con-

Dr Guérin and Mr Lachal are affiliated with Réanimation médicale, Hospices Civils de Lyon, Lyon, France. Drs Guérin and Louis are affiliated with INSERM U955 Créteil and CNRS ERL 7000 Créteil, Paris, France. Dr Subtil is affiliated with Service de Biostatistiques, Hospices civils de Lyon, and UMR CNRS 5558 - LBBE, Villeurbanne, France. Drs Subtil and Guérin are affiliated with Université de Lyon, Lyon, France. Dr Guérin is also affiliated with Médecine Intensive-Réanimation and INSERM 1042 HP2, Grenoble, France.

Supplementary material related to this paper is available at http:// www.rcjournal.com. tract. Third, the glottis opens and expiratory muscles contract, expelling air from the thorax with an air flow as high as $360-720 \mathrm{~L} / \mathrm{min}$. The cough peak flow is consequently higher than the peak expiratory flow (PEF) with an open glottis. ${ }^{3}$ An effective cough is defined by a cough peak flow $>180 \mathrm{~L} / \mathrm{min}$ or a PEF $>160 \mathrm{~L} / \mathrm{min}^{3}{ }^{3,4}$ To ensure such a high cough peak flow, the maximum expiratory pressure $\left(\mathrm{P}_{\text {Emax }}\right)$ must be $>60 \mathrm{~cm} \mathrm{H}_{2} \mathrm{O}$. $^{5-7}$

There are a number of chronic neuromuscular diseases in which low $\mathrm{P}_{\text {Emax }}$ is associated with low cough peak flow and hence a less effective cough. ${ }^{8}$ Acute

\footnotetext{
The authors have disclosed a relationship with Philips Healthcare France.

Correspondence: Claude Guérin, MD PhD, Médecine Intensive Réanimation Hopital de la Croix Rousse, 103 Grande Rue de la Croix Rousse, 69004 Lyon, France. E-mail: claude.guerin@chu-lyon.fr.
}

DOI: $10.4187 /$ respcare. 06478 
respiratory failure may occur as a result of impaired airway clearance in subjects with bulbar innervated muscle dysfunction or a respiratory tract infection and weak cough. Therefore, cough management is of paramount

\section{See the Related Editorial on Page 866}

importance in the setting of chronic neuromuscular disorders, and this involves the patient's family, physiotherapist, and respiratory therapist. ${ }^{9,10}$ One method to increase cough effectiveness is the use of a mechanical insufflation-exsufflation (MI-E) device. ${ }^{3,4,11-13}$ An MI-E device can mimic the cough process by increasing lung volume with positive pressure and then switching to negative pressure to reach a $\mathrm{P}_{\text {Emax }}$ sufficient to promote a PEF to enhance airway clearance. ${ }^{14}$ Use of MI-E devices has been recommended for neuromuscular subjects when the cough peak flow is $<270 \mathrm{~L} / \mathrm{min}^{15}$ because of the risk of falling to $<160 \mathrm{~L} / \mathrm{min}$ in case of infection. ${ }^{3}$ However, systematic reviews of available data do not support the routine use of MI-E devices in this setting. ${ }^{3,16}$

Collapsible upper airways can occur by partial or complete obstruction of the airway lumen, which will reduce cough peak flow and PEF for a given $\mathrm{P}_{\text {Emax }}$ compared to patent upper airways. Upper airways may partially or totally collapse in subjects with neuromuscular disorders or tracheobronchomalacia. To understand why MI-E may not be effective in all subjects with neuromuscular disease, it is important to understand the underlying mechanism of airway collapse for these subjects. Whereas tracheobronchomalacia is characterized by weak trachea/bronchial walls resulting in airway collapse, neuromuscular disorders with bulbar innervated muscle dysfunction may result in upper airway malfunctioning due to hypotony or spasticity, depending on the type of muscular paresis. Recently, Andersen et al ${ }^{17}$ observed that subjects with amyotrophic lateral sclerosis with bulbar involvement were particularly at risk of laryngeal closure, especially at the supra-glottic level, during the insufflation phase of MI-E treatment. This phenomenon also occurred during the exsufflation phase and was related to the high pressures used.

Therefore, we conducted a bench study to address findings shown by other investigators that collapse may occur in larger conducting airways during MI-E treatment. We assessed the effect of a collapsible tube on PEF generated with a MI-E device. It should be acknowledged from the onset that our model is limited as it is a simplified representation of conductive airways and thus cannot mimic movement, such as vocal cord adduction. The role of upper airway collapsibility has, however, not been investigated earlier in bench studies. Our hypothesis was that PEF would be lower with a

\section{QUICK LOOK}

\section{Current knowledge}

Mechanical insufflation-exsufflation devices are commonly used in the ICU or at home to help clear secretions in patients with weak cough, in particular those suffering from neuromuscular disease. The generated peak expiratory flow is one of the main determinants of device efficiency. It is assumed that peak expiratory flow is lower in patients with collapsible upper airways as opposed to patent upper airways.

\section{What this paper contributes to our knowledge}

We bench tested a range of pressures using a mechanical insufflation-exsufflation device with different compliance and resistance settings and a test lung with and without a collapsible tube. We found that peak expiratory flow was higher with the collapsible tube. We hypothesize that the walls of the tube accelerated flow during exsufflation from the device.

collapsible tube than without in accordance with clinical observations.

\section{Methods}

\section{Equipment}

The setup to assess the performance of an MI-E device with and without a collapsible tube included the following items (Fig. 1): an MI-E device (CoughAssist E70, Phillips Healthcare, Murrysville, Pennsylvania), which was provided by the manufacturer; a lung simulator (Training and Test Lung, Michigan Instruments, Grand Rapids, Michigan) with adjustable compliance (C) and the Pneuflo Resistor (R); a pneumotachograph (Fleish 4, Lausanne, Switzerland); a collapsible latex tube (AirComp Latex, Michelin, Clermont-Ferrand, France); a piezoresistive transducer (BD Gabarith, Vogt Medical, Vertrieb, Karlsruhe, Germany) to measure pressure at the proximal end of the tube; and a data logger (MP150, Biopac, Goleta, California). The MI-E device was assessed in a specific room in the ICU at the Croix Rousse University Hospital in Lyon, France. The physical properties of the collapsible tube were assessed in the INSERM laboratory of fluid mechanics in Créteil, France.

\section{Assessment of MI-E Performance}

The experiments were performed on room air at ambient temperature. The flow and pressure transducers were 


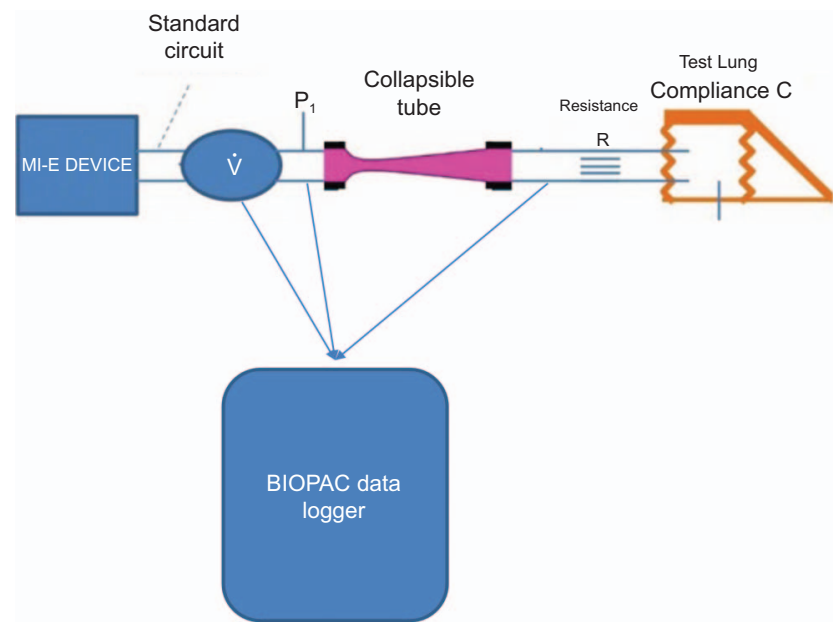

Fig. 1. Schematic representation of the setup used to assess the cough-assist device. $P_{1}$ is airway pressure measured proximal to the collapsible tube or proximal to the test lung when collapsible tube was not used. $\dot{V}=$ air flow.

calibrated in these conditions before the measurements. The CoughAssist E70 device was set in automatic mode with an inspiratory time of $3 \mathrm{~s}$, an expiratory time of $3.2 \mathrm{~s}$, and a 2-s pause between each cycle.

We tested six combinations of compliance (C) and resistance $(\mathrm{R})$, each with and without the collapsible tube: C20, C40, and C60 indicate compliance of 20, 40, and $60 \mathrm{~mL} / \mathrm{cm} \mathrm{H}_{2} \mathrm{O}$, respectively, and R5 and R20 indicate resistance of 5 and $20 \mathrm{~cm} \mathrm{H}_{2} \mathrm{O} / \mathrm{L} / \mathrm{s}$, respectively. For each $\mathrm{C}-\mathrm{R}$ combination, we applied inspiratory/expiratory pressures of $+30 /-30 \mathrm{~cm} \mathrm{H}_{2} \mathrm{O},+40 /-40 \mathrm{~cm} \mathrm{H}_{2} \mathrm{O}$, and $+50 /-50 \mathrm{~cm}$ $\mathrm{H}_{2} \mathrm{O}$. Each C-R combination was tested in random order. For each condition, the pressure and flow signals were continuously recorded at $200 \mathrm{~Hz}$ after a stabilization period of 3-4 MI-E actuations. We used the last $5 \mathrm{cy}-$ cles for the analysis.

\section{Characteristics of the Collapsible Tube}

The collapsible latex tube had a diameter of $18 \mathrm{~mm}$, a length of $15 \mathrm{~cm}$, and a thickness of $1 \mathrm{~mm}$ (Michelin, Clermont-Ferrand, France), and it was supported by a 22M22M straight connector (Intersurgical, Workingham, England) at either end.

\section{Data Analysis}

The data were analyzed using Acqknowledge software version 4.0 (Biopac). The combinations tested were entirely independent of each other. The main outcome measure was PEF. Our primary end point was the effect of the collapsible tube on PEF. In each C-R condition, with or without the collapsible tube in place, we systematically assessed PEF by measuring its maximum value during the first $100 \mathrm{~ms}$ after onset of expiration. The pressure was recorded during the same time window. The relationship of PEF to the corresponding measured pressure was determined using a linear regression model in each condition according to the following formulation:

$$
\operatorname{lm}\left(\mathrm{PEF}=\mathrm{P}_{\mathrm{Emax}} * \text { collapsible tube } * \mathrm{C}-\mathrm{R} \text { condition }\right)
$$

where $1 \mathrm{~m}$ is the linear regression function and the symbol * indicates interaction between the factors. This model assumes a linear relationship between $\mathrm{P}_{\mathrm{Emax}}$ and PEF. The extent to which the $\mathrm{C}-\mathrm{R}$ condition and collapsible tube modified the linear relationship (ie, intercept and slope as discussed below) of $\mathrm{P}_{\mathrm{Emax}}$ to PEF was explored by the interaction terms. The intercept is the value of PEF at a pressure of $30 \mathrm{~cm} \mathrm{H}_{2} \mathrm{O}$, and the slope is the rate of change of PEF per $1 \mathrm{~cm} \mathrm{H}_{2} \mathrm{O}$ change in pressure. For each C-R condition, the output of the linear regression analysis reflected the intercept and the slope without the collapsible tube as a reference value, and then the linear regression analysis reflected the effect of the collapsible tube on both the intercept and the slope.

Data are shown as mean \pm SD unless otherwise stated. A $P$ value $<.05$ was set as the statistical significance threshold. The statistical analysis was performed by using RStudio software version 1.0.153 (RStudio, Boston, Massachusetts).

\section{Simulation of the Collapsible Tube Lung Test System}

To interpret our experimental results, we performed a simulation in which the collapsible tube was modeled as a discrete compliant element with various $\mathrm{C}-\mathrm{R}$ conditions modeled on the test lung (see the supplementary materials at http://www.rcjournal.com). The conservation of both total pressure (per the generalized Bernoulli's formula) and flow, at the level of the pressure tape $\mathrm{P}_{1}$ and at the level of the compliant element associated with the steadystate law gives a system of 2 equations linking steady pressure variation $\left(\mathrm{P}_{1}\right)$, volume, flow, $\mathrm{R}, \mathrm{C}$, and crosssectional area (see the supplementary materials at http:// www.rcjournal.com). In steady-state conditions, that is, for a given value of $\mathrm{P}_{1}, \mathrm{R}$, and $\mathrm{C}$, determination of the flow across the model and the cross-sectional area may be numerically inferred. This numerical resolution uses a dichotomy procedure as described by Fodil and colleagues. ${ }^{18,19}$ Due to the steady-state condition resolution limitation (see the supplementary materials at http:// www.rcjournal.com), we added the flow induced by the volume displacement of the collapsible tube wall to this solution. We recorded a video picturing the collapsible tube from the outside to show its behavior during insuf- 

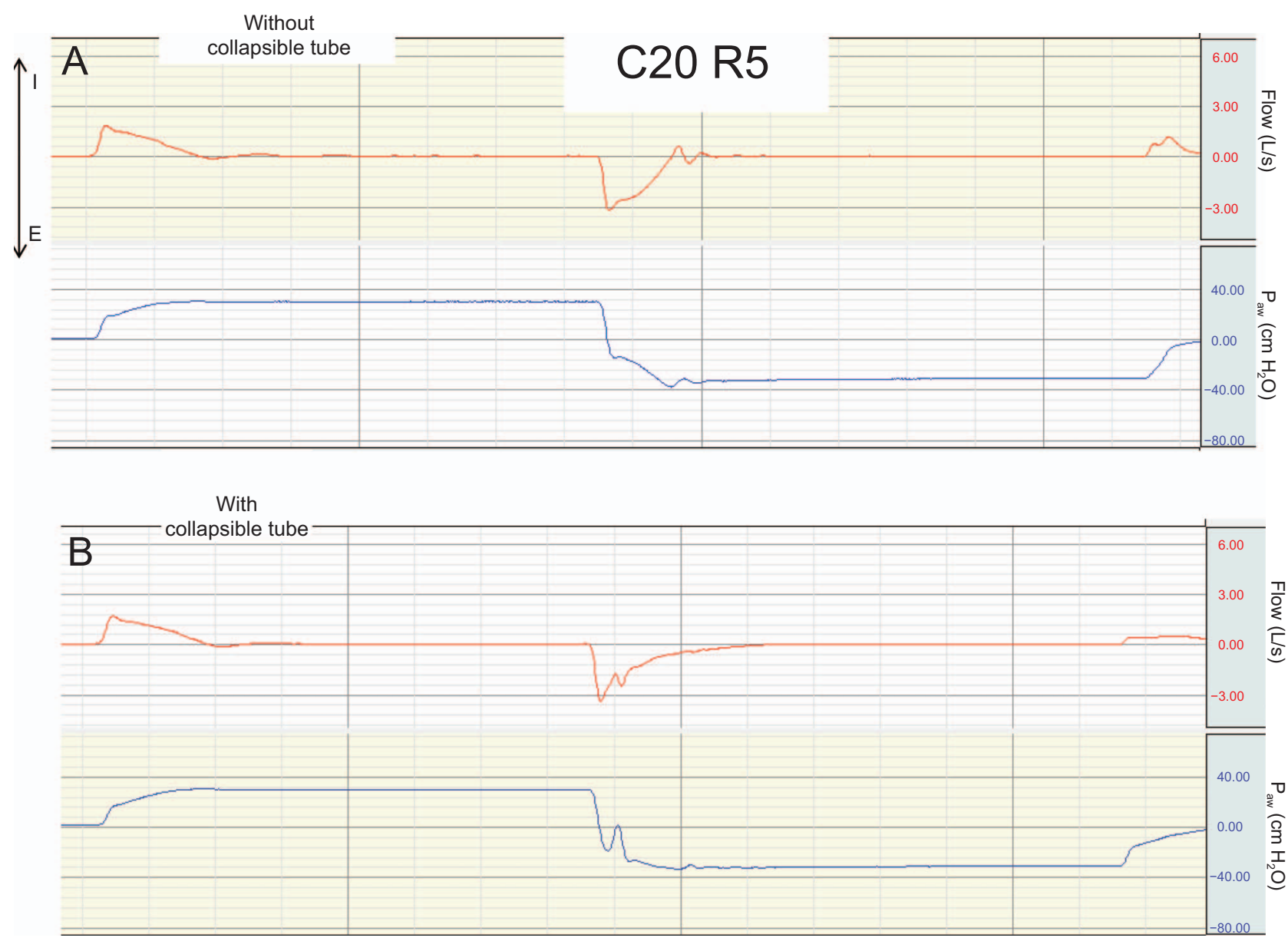

Fig. 2. Flow and $\mathrm{P}_{\mathrm{aw}}(\mathrm{A})$ with and $(\mathrm{B})$ without a collapsible tube at a set pressure of $30 \mathrm{~cm} \mathrm{H}_{2} \mathrm{O}$. The direction of inspiration (I) and expiration (E) is shown by arrows at the upper left. $\mathrm{P}_{\text {aw }}=$ airway pressure; $\mathrm{C} 20-\mathrm{R} 5=$ the condition of $20 \mathrm{~mL} / \mathrm{cm} \mathrm{H}_{2} \mathrm{O}$ compliance and $5 \mathrm{~cm} \mathrm{H}_{2} \mathrm{O} / \mathrm{L} / \mathrm{s}$ resistance.

flation and exsufflation with the MI-E device (see the supplementary materials at http://www.rcjournal.com).

\section{Results}

\section{Effect of the Collapsible Tube}

This part of the experiment involved 180 measurements ( 2 tube conditions $\times 6$ lung mechanical conditions $\times 3$ pressure levels $\times 5$ breaths). Recordings showed that, for some C-R conditions, $\mathrm{P}_{\mathrm{Emax}}$ was delayed without the collapsible tube and that the collapsible tube resulted in fluctuations in expiratory flow for the same set $\mathrm{P}_{\text {Emax }}$ (Fig. 2). These findings were adequately taken into account by our choice to record PEF within the first $100 \mathrm{~ms}$ of exsufflation. The relationships of PEF to airway pressure for every $\mathrm{C}-\mathrm{R}$ condition with and without the collapsible tube are displayed in Figure 3. Contrary to our hypothesis, PEF was higher with the collapsible tube than without for every $\mathrm{C}-\mathrm{R}$ condition. The results of the linear regression analysis are summarized in Table 1. For the $\mathrm{C} 20-\mathrm{R} 5$ condition, the effect of the collapsible tube on the intercept $\left(-0.35 \mathrm{~cm} \mathrm{H}_{2} \mathrm{O}\right)$ was not significant, but this was offset by a significant (and the largest) increase in slope $\left(+0.12 \mathrm{~L} / \mathrm{s} / \mathrm{cm} \mathrm{H}_{2} \mathrm{O}\right)$. For the C60-R20 condition, the effect of the collapsible tube on the slope $\left(-0.003 \mathrm{~L} / \mathrm{s} / \mathrm{cm} \mathrm{H}_{2} \mathrm{O}\right)$ was not significant, but this was offset by a significant (and the largest) increase of the intercept $\left(+3.16 \mathrm{~cm} \mathrm{H}_{2} \mathrm{O}\right)$ at expiratory pressure of $30 \mathrm{~cm} \mathrm{H}_{2} \mathrm{O}$. For the other conditions, the collapsible tube significantly increased PEF at expiratory pressure of $30 \mathrm{~cm} \mathrm{H}_{2} \mathrm{O}$, and the gap further increased above this pressure as shown by the increased slope. Therefore, the gain in PEF with the collapsible tube increased continuously over the range of pressure investigated. The effect of the collapsible tube was different depending on the $\mathrm{C}-\mathrm{R}$ condition in terms of both intercept and slope $(P<.001)$. The predicted values of PEF are shown in Table 2.

The collapsible tube also modified the pattern of the pressure at the output of the MI-E device for the same set pressure (Fig. 2) because the MI-E device seemed to stop 

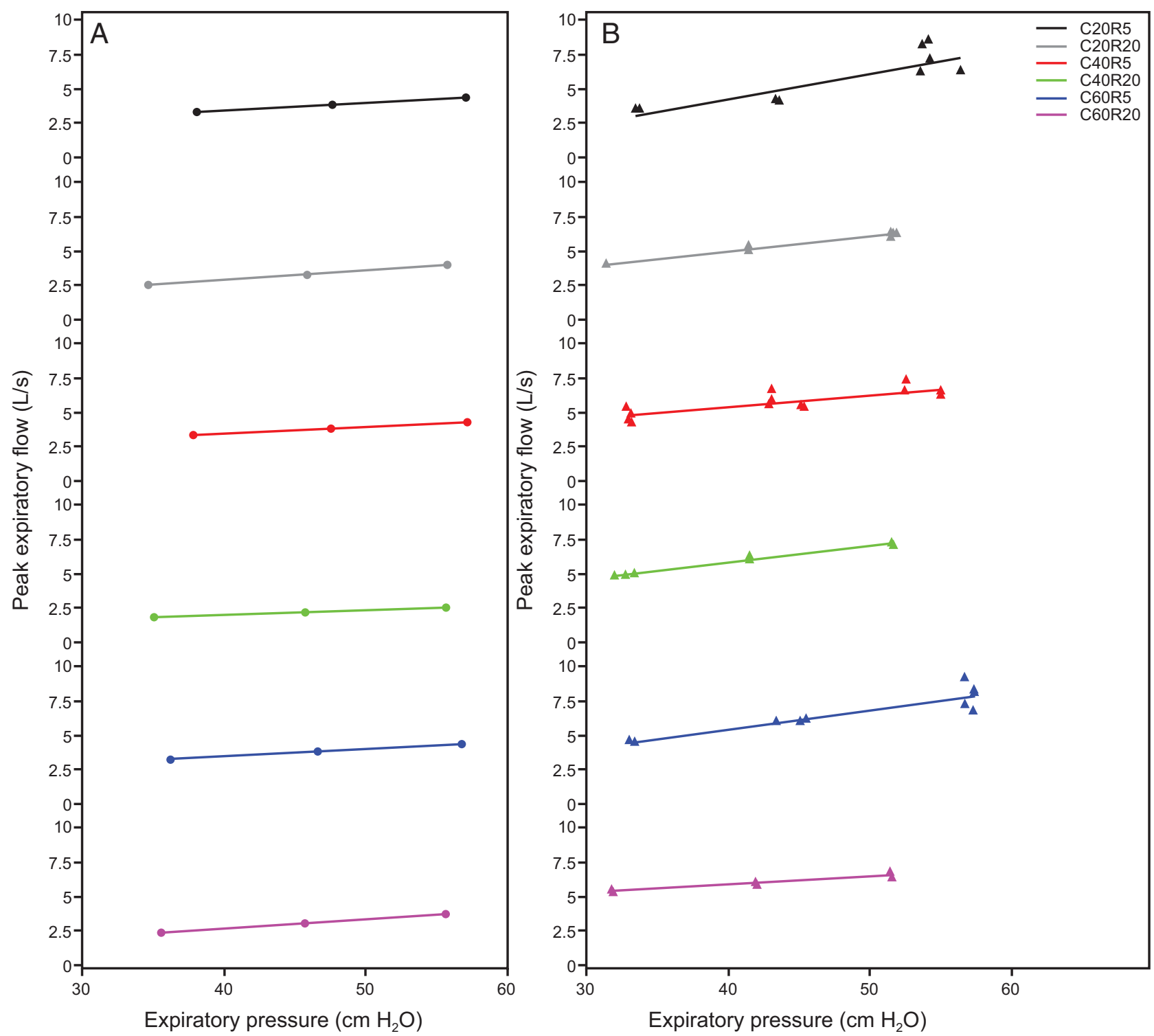

Fig. 3. Relationships of peak expiratory flow to maximum expiratory pressure $(A)$ without a collapsible tube and (B) with a collapsible tube in the 6 combinations of compliance $(C)$ and resistance $(R)$. Continuous lines are regression lines.

or decrease depressurization briefly with the collapsible tube. We also observed variations in the pressure patterns without the collapsible tube along with the change in C-R combinations (see the supplementary materials at http:// www.rcjournal.com).

\section{Simulations}

The simulations showed that PEF was lower with the collapsible tube than without in the quasi-steady-state conditions. This result was inversed by taking into account the wall displacement to roughly mimic the flow observed. The collapsible tube started closing at the upstream end (ie, at the MI-E device side) at the time of the delivery of exsufflation, and this closure then propagated downstream toward the test lung before eventually reopening (see the supplementary materials at http://www.rcjournal.com).

\section{Discussion}

The main finding of this bench study was that, contrary to our hypothesis, PEF was higher with the collapsible tube than without in our model. To our knowledge, this study is the first to provide bench data with the CoughAssist E70 device, and thus we cannot compare our results directly with others. However, we previously tested the former device (CoughAssist, Philips Respironics) in vitro just before the release of the CoughAssist E70 ${ }^{17,18}$ and 
Table 1. Effect of Collapsible Tube on the Linear Regression Model Between PEF and Pressure

\begin{tabular}{|c|c|c|}
\hline \multirow[b]{2}{*}{$\begin{array}{c}\text { Compliance-Resistance } \\
\text { Condition }\end{array}$} & \multicolumn{2}{|c|}{ Effect of Collapsible Tube } \\
\hline & $\begin{array}{l}\text { Change in } \\
\text { Intercept } \\
\text { at } 30 \mathrm{~cm} \mathrm{H}_{2} \mathrm{O}\end{array}$ & $\begin{array}{l}\text { Change } \\
\text { in Slope }\end{array}$ \\
\hline C20-R5 & -0.35 & $+0.12 *$ \\
\hline C20-R20 & $+1.74 *$ & $+0.03 *$ \\
\hline C40-R5 & $+1.42 *$ & $+0.04 *$ \\
\hline C40-R20 & $+2.84 *$ & $+0.09 *$ \\
\hline C60-R5 & $+1.08^{*}$ & $+0.08^{*}$ \\
\hline C60-R20 & $+3.16^{*}$ & -0.003 \\
\hline $\begin{array}{l}{ }^{* P}<.05 \\
\mathrm{PEF}=\text { peak expiratory flow } \\
\mathrm{C}=\text { compliance } \\
\mathrm{R}=\text { resistance }\end{array}$ & & \\
\hline
\end{tabular}

found similar PEF values for an $\mathrm{P}_{\mathrm{Emax}}$ of $30 \mathrm{~cm} \mathrm{H}_{2} \mathrm{O}$ using same test lung and measurement devices. ${ }^{20,21}$ This suggests that the present data without the collapsible tube are consistent and accurate.

A previous bench study demonstrated that the efficiency of an MI-E device is impaired by an endotracheal tube or a tracheotomy cannula compared to no artificial airway. ${ }^{20}$ Furthermore, MI-E device impairment is related to the internal diameter of the artificial airway, ie, the narrower the tracheal prosthesis, the greater the reduction of PEF for a given $\mathrm{P}_{\text {Emax }}{ }^{20,22}$ This finding has clinical implications, in particular for intubated or tracheotomized patients in an ICU.

To our knowledge, the role of collapsibility of the conducting airways has not previously been tested in a bench study. From a clinical perspective, both respiratory therapists and physiotherapists experience problems with MI-E devices in subjects with neuromuscular diseases..$^{23,24}$ These providers regularly observe that insufflation and exsufflation are associated with a so-called upper airway muscle spasm or vocal cord closure, making the treatment ineffective in removing airways secretions. Recently, the visualization of the glottis in subjects with amyotrophic lateral sclerosis during use of an MI-E device shed some light on these clinical observations and provided evidence of a negative effect of the device during the insufflation phase. ${ }^{17}$ Insufflation promoted mainly the adduction of aryepiglottic folds in subjects with bulbar involvement, but also adduction of vocal folds after initial abduction in subjects with amyotrophic lateral sclerosis with or without bulbar symptoms. ${ }^{17}$ This could explain why PEF can be lower than expected with an MI-E device. ${ }^{1}$ However, in subjects without bulbar innervated muscle dysfunction, higher values of PEF were obtained with MI-E than with any other method of cough enhancement. ${ }^{11}$ Others have reported an improvement in lung volumes by using MI-E in subjects with neuromuscular disease. ${ }^{25}$ All in all, these contradictory findings are not surprising because neuromuscular subjects are a highly heterogeneous group. This also explains why systematic reviews do not recommend the use of MI-E treatment in subjects with neuromuscular disorders and call for randomized controlled trials of good quality. ${ }^{26}$

Our bench study is an oversimplification of real events occurring in humans. The conducting airways consist of several components (eg, glottis, larynx, bronchi) incorporating rigid cartilage skeletons, ligaments, and muscles for adduction and abduction. The results of this study are also applicable to the situations where the trachea or major bronchi may be collapsible. not just the larynx. However, diseases affecting the upper airway musculature are complex diseases involving several mechanisms, such as neurological elements of hypotony and spasticity, and therefore the results of this study are difficult to translate to real subjects. We attempted to explain our findings by performing a theoretical simulation of the behavior of the collapsible tube. The results of the simulation suggest that the walls of the tube accelerated the flow during exsufflation from the MI-E device. Clearly, the simulation of the collapsible tube by a discrete compliant element is also an oversimplification. Nevertheless, if we take into account the role of wall displacement in the flow, that is, if we introduce non-steady-state conditions for the resolution, we can describe the flow (with its peak) and explain why PEF was higher with the collapsible tube. The non-steadystate conditions for the resolution are important because they mean that the flow (and the PEF) is not necessarily maintained along the airway tree (ie, from the MI-E device to the lung model). Downstream (ie, toward the lung model) the presence of the collapsible tube tends to decrease the PEF, whereas upstream it tends to increase PEF due to the additional flow coming from the tube wall displacement. The effect of this phenomenon varies as the different parameters (eg, collapsibility, medium around the collapsible segment, among others) vary, and it is difficult to evaluate its importance in real subjects. However, it suggests that a high PEF value recorded at the airway opening is not necessarily a guarantee of efficiency throughout the tracheobronchial tree. It also suggests that cough flow is probably more efficient in generating "positive" pressure throughout the airways than an MI-E (or similar) device that generates "negative" pressure potentially under the closing pressure. Individually customized settings can facilitate this. ${ }^{17,27}$

The pressure pattern observed with the collapsible tube is probably an indication of how the MI-E device prevented potential airway collapse and its associated flow limitation. In other words, such behavior tends to protect the airways from a mechanically-induced collapse due to the MI-E device. Without a complete description of the 
Table 2. Predicted Values of PEF in Each Compliance-Resistance Condition for Each Nominal Set Pressure With and Without Collapsible Tube

\begin{tabular}{|c|c|c|c|c|c|c|}
\hline \multirow{2}{*}{$\begin{array}{c}\text { Compliance-Resistance } \\
\text { Condition }\end{array}$} & \multicolumn{3}{|c|}{ PEF Without Collapsible Tube, L/s } & \multicolumn{3}{|c|}{ PEF With Collapsible Tube, L/s } \\
\hline & $30 \mathrm{~cm} \mathrm{H}_{2} \mathrm{O}$ & $40 \mathrm{~cm} \mathrm{H}_{2} \mathrm{O}$ & $50 \mathrm{~cm} \mathrm{H}_{2} \mathrm{O}$ & $30 \mathrm{~cm} \mathrm{H}_{2} \mathrm{O}$ & $40 \mathrm{~cm} \mathrm{H}_{2} \mathrm{O}$ & $50 \mathrm{~cm} \mathrm{H}_{2} \mathrm{O}$ \\
\hline C20-R5 & 2.69 & 3.29 & 3.89 & 2.34 & 4.14 & 5.94 \\
\hline $\mathrm{C} 20-\mathrm{R} 20$ & 2.07 & 2.77 & 3.47 & 3.74 & 4.74 & 5.74 \\
\hline C40-R5 & 3.07 & 3.57 & 4.07 & 4.46 & 5.36 & 6.26 \\
\hline $\mathrm{C} 40-\mathrm{R} 20$ & 1.73 & 2.03 & 2.33 & 4.52 & 5.72 & 6.92 \\
\hline C60-R5 & 2.73 & 3.23 & 3.73 & 3.94 & 5.34 & 6.74 \\
\hline C60-R20 & 2.14 & 2.84 & 3.54 & 5.38 & 6.08 & 6.78 \\
\hline $\begin{array}{l}\mathrm{PEF}=\text { peak expiratory flow } \\
\mathrm{C}=\text { compliance } \\
\mathrm{R}=\text { resistance }\end{array}$ & & & & & & \\
\hline
\end{tabular}

present MI-E device software, it is difficult to pinpoint the exact parameters that initiate such a behavior. Nevertheless, the fact that in rigid conditions an increase of the $\mathrm{C} \times$ $\mathrm{R}$ product decreases the depressurization velocities (Fig. A5 in the supplementary materials at http://www.rcjournal. com) may suggest that MI-E devices use the relation between flow and pressure to adapt its output pressure.

Transposed into the clinical field and considering the observations made in subjects with amyotrophic lateral sclerosis, ${ }^{17}$ our results indicate that the issue in such subjects is to open the upper airways rather than to expel air during the expiratory phase. The $\mathrm{C}-\mathrm{R}$ combinations used in this bench study aimed to cover a large range of clinical conditions encountered in the ICU or in out-patients with various ventilator functional patterns (see Table A1 in the supplementary materials at http://www.rcjournal.com). The compliance used in this study may refer to the whole respiratory system or to its lung component only. Given the limitations of our model, these results should not change the current practice. However, these results should encourage caregivers to customize the settings of the MI-E device, in particular by lowering inspiratory flow to facilitate insufflation. In patients with endotracheal intubation or tracheotomy, the upper airways are bypassed and cannot collapse. However, cartilaginous airways below the tracheal prosthesis may well collapse if they exhibit malacia. The real incidence of bronchomalacia in ICU patients under invasive mechanical ventilation is largely unknown. In ICU patients with an artificial airway, MI-E treatment has been shown to be safe and effective. ${ }^{28}$ While this finding does not validate our results per se, it does support them.

Apart from the fact that our model is an oversimplification of the anatomy and physiologic behavior of upper airways in humans, a further limitation is that different results may have been obtained by using a different collapsible tube. Further bench research should be performed on human or animal tracheas with the same set up as our study, as well as further investigation of the velocity pro- file of air during MI-E actuation. Human cadavers treated with the Thiel technique, ${ }^{29}$ which preserves tissue elasticity, may be a much more realistic approach to investigate this problem. Finally, the upper airways could be directly, dynamically, and noninvasively assessed during the MI-E procedure with modern imaging techniques. ${ }^{30}$ In conclusion, we found that PEF was higher with a collapsible tube than without a collapsible tube at all respiratory mechanics profiles tested.

\section{ACKNOWLEDGMENT}

The authors thank Philips Healthcare France for providing E70 device for the experiment.

\section{REFERENCES}

1. Toussaint M, Boitano LJ, Gathot V, Steens M, Soudon P. Limits of effective cough-augmentation techniques in patients with neuromuscular disease. Respir Care 2009;54(3):359-366.

2. Boitano LJ. Management of airway clearance in neuromuscular disease. Respir Care 2006;51(8):913-922.

3. Auger C, Hernando V, Galmiche H. Use of mechanical insufflationexsufflation devices for airway clearance in subjects with neuromuscular disease. Respir Care 2017;62(2):236-245.

4. Chatwin M, Toussaint M, Goncalves MR, Sheers N, Mellies U, Gonzales-Bermejo J, et al. Airway clearance techniques in neuromuscular disorders: a state of the art review. Respir Med 2018;136: 98-110.

5. Panitch HB. Airway clearance in children with neuromuscular weakness. Curr Opin Pediatr 2006;18(3):277-281.

6. Finder JD, Birnkrant D, Carl J, Farber HJ, Gozal D, Iannaccone ST, et al. Respiratory care of the patient with Duchenne muscular dystrophy: ATS consensus statement. Am J Respir Crit Care Med 2004; 170(4):456-465.

7. Kravitz RM. Airway clearance in Duchenne muscular dystrophy. Pediatrics 2009;123(Suppl 4):S231-5235.

8. Bach JR. Update and perspective on noninvasive respiratory muscle aids. Part 2: The expiratory aids. Chest 1994;105(5):1538-1544.

9. Moran FC, Spittle AJ, Delany C. Lifestyle implications of home mechanical insufflation-exsufflation for children with neuromuscular disease and their families. Respir Care 2015;60(7):967-974.

10. Denehy L, Berney S. The use of positive pressure devices by physiotherapists. Eur Respir J 2001;17(4):821-829. 


\section{Collapsible Tube With an Mi-E Device}

11. Chatwin M, Ross E, Hart N, Nickol AH, Polkey MI, Simonds AK. Cough augmentation with mechanical insufflation/exsufflation in patients with neuromuscular weakness. Eur Respir J 2003;21(3):502508.

12. Chatwin M, Simonds AK. The addition of mechanical insufflation/ exsufflation shortens airway-clearance sessions in neuromuscular patients with chest infection. Respir Care 2009;54(11):1473-1479.

13. Toussaint M, Chatwin M, Gonzales J, Berlowitz DJ. 228th ENMC International Workshop: airway clearance techniques in neuromuscular disorders. Neuromuscul Disord 2018;28(3):289-298.

14. Sorenson HM, Shelledy DC. AARC clinical practice guideline. Intermittent positive pressure breathing-2003 revision \& update. Respir Care 2003;48(5):540-546.

15. Bach JR, Ishikawa Y, Kim H. Prevention of pulmonary morbidity for patients with Duchenne muscular dystrophy. Chest 1997;112(4): 1024-1028.

16. Rose L, Adhikari NK, Leasa D, Fergusson DA, McKim D. Cough augmentation techniques for extubation or weaning critically ill patients from mechanical ventilation. Cochrane Database Syst Rev 2017;1:CD011833.

17. Andersen T, Sandnes A, Brekka AK, Hilland M, Clemm H, Fondenes $\mathrm{O}$, et al. Laryngeal response patterns influence the efficacy of mechanical assisted cough in amyotrophic lateral sclerosis. Thorax 2017;72(3):221-229.

18. Fodil R, Brugel-Ribere L, Croce C, Sbirlea-Apiou G, Larger C, Papon $\mathrm{JF}$, et al. Inspiratory flow in the nose: a model coupling flow and vasoerectile tissue distensibility. J Appl Physiol 2005;98(1):288-295.

19. Fodil R, Ribreau C, Louis B, Lofaso F, Isabey D. Interaction between steady flow and individualised compliant segments: application to upper airways. Med Biol Comput 1997;35:638-648.

20. Guérin C, Bourdin G, Leray V, Delannoy B, Bayle F, Germain M, et al. Performance of the CoughAssist insufflation-exsufflation device in the presence of an endotracheal tube or tracheostomy tube: a bench study. Respir Care 2011;56(8):1108-1114
21. Porot V, Guerin C. Bench assessment of a new insufflation-exsufflation device. Respir Care 2013;58(9):1536-1540

22. Toussaint M. The use of mechanical insufflation-exsufflation via artificial airways. Respir Care 2011;56(8):1217-1219.

23. Flandreau G, Bourdin G, Leray V, Bayle F, Wallet F, Delannoy B, et al. Management and long-term outcome of patients with chronic neuromuscular disease admitted to the intensive care unit for acute respiratory failure: a single-center retrospective study. Respir Care 2011;56(7):953-960

24. Guérin C, Vincent B, Petitjean T, Lecam P, Luizet C, Rabilloud M, et al. The short-term effects of intermittent positive pressure breathing treatments on ventilation in patients with neuromuscular disease. Respir Care 2010;55(7):866-872.

25. Stehling F, Bouikidis A, Schara U, Mellies U. Mechanical insufflation/exsufflation improves vital capacity in neuromuscular disorders. Chron Respir Dis 2015;12(1):31-35

26. Morrow B, Zampoli M, van Aswegen H, Argent A. Mechanical insufflation-exsufflation for people with neuromuscular disorders. Cochrane Database Syst Rev 2014(12):CD010044.

27. Andersen TM, Sandnes A, Fondenes O, Nilsen RM, Tysnes OB, Heimdal $\mathrm{JH}$, et al. Laryngeal responses to mechanically assisted cough in progressing amyotrophic lateral sclerosis. Respir Care 2018; 63(5):538-549.

28. Sanchez-Garcia M, Santos P, Rodriguez-Trigo G, Martinez-Sagasti F, Farina-Gonzalez T, Del Pino-Ramirez A, et al. Preliminary experience on the safety and tolerability of mechanical "insufflationexsufflation" in subjects with artificial airway. Intensive Care Med Exp 2018;6(1):8.

29. Thiel W. The preservation of the whole corpse with natural color. Ann Anat 1992;174(3):185-195.

30. Kim M, Collier GJ, Wild JM, Chung YM. Effect of upper airway on tracheobronchial fluid dynamics. Int J Numer Method Biomed Eng 2018;e3112.

This article is approved for Continuing Respiratory Care Education credit. For information and to obtain your CRCE

(free to AARC members) visit

www.rcjournal.com

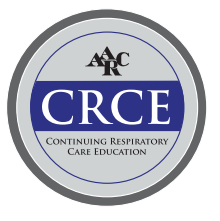

